\title{
INDRUK VAN SURINAME
}

DOOR

\section{IR. IMAN G. J. VAN DEN BOSCH}

Bij een kort bezoek aan onze Kolonie „Suriname” was het mij hoofdzakelijk te doen om de groot-cultuur, daar deze in het economische leven van de kolonie de grootste rol speelt, feitelijk den financieelen toestand beheerscht.

Aan hetgeen ik te voren over Suriname had gehoord en gelezen, is mij deze kolonie meêgevallen en ik kreeg den indruk, dat de nadeelen tegenover de voordeelen wel zeer breed worden uitgemeten, hetgeen er zeer toe heeft medegewerkt, dat de kolonie een minder gunstigen naam heeft gekregen.

Allereerst zag ik natuurlijk het stadje Paramaribo. Veel netter en zindelijker dan ik had verwacht! Wanneer men van Curaçao komt is het treffend hoe in Suriname bijkans iedereen onze taal spreekt en het is heel zuiver Nederlandsch, dat over het algemeen gesproken wordt. In dit opzicht is dus het onderwijs zeker niet te kort geschoten. En dit is van groot belang! Immers, de taal werkt door in de volksziel. Deze is dus Nederlandsch, zooals voor een Nederlandsche kolonie past. Natuurlijk hebben de Surinamers hun eigen aard en eigenaardigheden, verband houdende met levensomstandigheden en bloedmenging. Ik meende te ontdekken een sterke saamhoorigheid en onderlinge hulpvaardigheid, waarin een groote kracht ligt, vooral in tijden van tegenspoed. $\mathrm{Zij}$ hebben bovendien een zekere, vriendelijk tegemoetkomendheid, die aangenaam aandoet.

Naast de Surinamers staan de Nederlandsche Ambtenaren, aangewezen voor het in gang houden van het Bestuursapparaat ${ }^{1}$ ). Zij komen en gaan, daar Suriname voor eene blijvende vestiging niet aantrekkelijk (zooals bijv. Trinidad) schijnt te zijn, iets, wat zeker niet in het voordeel van de kolonie is. De ijver en toewijding waarmede zij hun taak vervullen laat in het algemeen niets te wenschen over. Doch niet altijd heeft vroegere positie of vóór-op-

1) Groot, omdat Suriname nu eenmaal een oppervlakte heeft van $4,5 \times$ ons land. 
leiding een'voldoende leerschool gevormd voor de in Suriname aanvaarde taak. Dit leidt dan tot mistasten bij een, overigens goed bedoeld streven, waaruit over en weer teleurstelling voortvloeit, soms zelfs een, vaak niet gerechtvaardigd, gevoel van miskenning, als gevolg waarvan de objectiviteit bij de beoordeeling van personen en toestanden wel eens in het gedrang komt. Wrijving tusschen bestuurders en bestuurden vindt dan ook in den regel meer haar oorsprong in onderling niet-begrijpen dan in onwelwillende gezindheid. Intusschen blijft zulke wrijving altijd te betreuren, daar samenwerking ten zeerste noodig is om het land vooruit te brengen en wrijving niet geschikt is de atmosfeer te scheppen waarin samenwerking gedijen kan.

Uit den aard der zaak is er een nauw contact tusschen de ambtenaren en het plantageleven, aangezien de voorziening in de behoefte aan plantage-arbeiders geheel door tusschenkomst van de Overheid geschiedt. In verband daarmede moeten de planters aan een reeks van voorschriften ten aanzien van behuizing, voeding en sanitaire verzorging voldoen. Ambtenaren oefenen daarop toezicht uit en aangezien niet altijd de handhaving van die voorschriften gericht wordt naar bijzondere omstandigheden, die op een bepaalde plantage voorliggen, ontstaat er dikwijls veel wrijving, vooral wanneer een ambtenaar een verlicht moment krijgt voor eene nieuwigheid, die $h i j$ als verbetering, maar de planter als een drukkende last beschouwt. Vooral nu de plantages een moeielijke overgangsperiode doormaken, de gezagvoerder tracht te bezuinigen, zelfs, als het kan te knijpen, zeer in den geest van den eigenaar in Holland, is hij gevoelig, zoo niet overgevoelig voor het contact met de ambtenarij.

Met dien overgang bedoel ik de omzetting van de cacao- in een koffie-plantage. Dit vereischt veel kapitaal en eer de koffievelden op volle productie zijn moet er jaren (7) gewacht worden, m.a.w. groote uitgaven gedurende een lange periode en daarnaast geringe inkomsten, eene financieele moeielijkheid, die sterker wordt gevoeld naarmate de koffieprijzen dalen. En deze zijn sedert 1928 sterk gedaald, met het gevolg, dat vele plantages in verdrukking komen, te meer, daar meestal geen voldoend reservekapitaal voorhanden is, omdat een overschot diende voor uitbreiding van de cultuur of wel vloeide in de kas van den uitheemschen eigenaar, die het niet bewaarde om het in slechte tijden te kunnen uitzingen. Het wordt wel eens te veel vergeten dat, zoodra er in de kolonie geld wordt gemaakt, dit er niet blijft en dus niet tot de welvaart van de kolonie bedraagt. De eigenaars van de plantages blijven 
zich op een zuiver koloniaal standpunt stellen en beschouwen dus Suriname als een Wingewest. Ook de Chinees, die de blanke winkelstand ondermijnt, daarbij profiteerende van onze vrijheidsbeginselen.

In de gegeven omstandigheden tracht men de productiekosten te verlagen door o.a. kleine plantages samen te voegen en zoodoende te werken op groote schaal. Daardoor verminderen de algemeene onkosten, die in Suriname hoog zijn tengevolge van het hooge gebouwenkapitaal, noodig om te voldoen aan de door de Regeering gestelde behuizings- en verplegingseischen. Deze algemeene onkosten drukken zeer op het bedrijf en plaatsen den Surinaamschen planter in veel ongunstiger positie dan zijn OostIndischen collega. Deze laatste heeft, althans op Java, bovendien nog het voordeel van lagere loonen, omdat onze Oost een groote bevolking heeft, waaruit de arbeidskrachten kunnen worden gerecruteerd. De Regeering stelt als basis een minimum loon van 80 cent per dag, waar in Oost-Indië voor contractarbeid 42 cent wordt betaald. Ook tracht men de bewerking van de koffie, die nu geschiedt in een aantal kleine fabriekjes, meer te concentreeren en tevens hoopt men in staat te zijn, door een gewijzigd procédé in de fabrikatie, de kwaliteit van de koffie te verbeteren, een meer gelijkvormig product te krijgen en zoodoende den afzet van de Surinaamsche Liberiakoffie te vergrooten, alsmede betere prijzen te maken. Er is, n.m.l. aan de koffie nog een bijsmaak, die men tracht weg te nemen, iets waarin men zelts ten deele is geslaagd. Tot nog toe wordt de Surinaamsche koffie hoofdzakelijk verkocht naar Scandinavië, maar deelt nog niet in een algemeenen afzet.

De omstandigheden waäronder gewerkt wordt, zijn dus niet gemakkelijk. Een lichtpunt is echter, dat in het algemeen de stand van de koffie te velde zeer bevredigend is.

Op het prachtige poldergebied ${ }^{1}$ ) van Suriname - en daarmede hebben wij hoofdzakelijk te rekenen - gedijt de koffieboom naast zijn koffiemama, (Erytrina) voor schaduw en voor stikstof verrijking van den bodem, uitstekend. Ik zag er boomen van 15 jaar oud, die $5 \mathrm{M}$. hoog zijn en men rekent een gemiddelde opbrengst van 1 K.G. koffie per boom, d.i. dus 300 K.G. of 3 balen per akker ( 1 akker $=$ ruim ${ }^{2} / 5$ H.A. $= \pm 1$ Friesche pondemaat). Natuurlijk zijn de koffievelden van verschillenden leeftijd en loopt de verhouding van voldragende, halfdragende en nog weinig dragende boomen

1) Zie voor oppervlakte het verslag van het Suriname studie Syndicaat van 1920 . 
zeer uiteen, zoodat de opbrengstcijfers van de plantages onderling, moeielijk vergelijkbaar zijn en de capaciteit van elke plantage afzonderlijk nog niet vast staat. Zoodra het hoogste stadium van productie is bereikt, is te hopen, dat de koffieprijzen inmiddels verbeterd zijn en dan kon wel eens blijken, dat de groote cultuur zich in opgaande lijn gaat bewegen. Dat de groote landbouw, zijn sterke "ups" and ,downs" heeft, ligt in het wezen eener eenzijdige cultuur met haar sterk speculatief karakter. Ziet men daartegen niet op, dan moet men ook de consequenties dragen en niet doen alsof men bijster ongelukkig is, indien de hoog-conjunctuur niet blijft aanhouden. Het is zeer jammer, dat de bacovencultuur werd opgegeven ${ }^{1}$ ), tengevolge van de Panamaziekte in de GrosMichel variëteit, die daarvoor bijzonder vatbaar is. Deze cultuur ging gemakkelijk, was niet duur en verdeelde de risico, die nu op één cultuur (de koffie) wordt gezet. De Suikercultuur bepaalt zich nog maar tot 5 plantages en is dus gedaald van een algemeene tot een bijzondere cultuur, die in den economischen toestand althans geen hoofdrol meer speelt. Wel blijft de suikercultuur voor de kolonie van beteekenis, ware het alleen, omdat de Nederl.

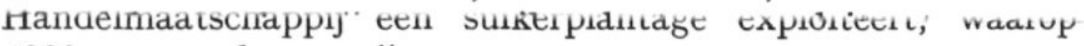
4000 man werkzaam zijn.

Het zijn dan ook vooral de kleine plantages, die het zeer moeilijk hebben. Maar of de plantages klein of groot zijn, altijd zijn het mooie, interessante bedrijven. Te bewonderen valt het prachtige afwateringswerk, eertijds door de Hollanders verricht. De oude sluizen functioneeren nog steeds onfeilbaar en ingenieurs brengen een eeresaluut aan den ouden technicus, onder wiens leiding ze zijn gemaakt.

Bij het ontginningswerk heeft men echter niet voorzien hoe het een behoefte $z o u$ worden de plantages te voorzien van wegen. Alle transport ging te water, binnen de plantage door een groote vaart, die men door een extra sluis op peil houdt en buiten de plantage op de rivier, waaraan alle plantages zijn gelegen. De groote Canoes verdwenen echter met de goedkoope roeiers, doch daar de aanleg van een wegennet ontbrak werd het verkeer zeer gehandicapt. Feitelijk behoorde het verkeer mogelijk te zijn langs goede wegen, maar de verbindingswegen, die men over de dijken heeft gemaakt, zijn voor autoverkeer te smal. Bovendien, harde wegen worden bij gebrek aan geschikt materiaal in Suriname zeer

$\left.{ }^{1}\right)$ Het is zeer de vraag of men met de opheffing niet wat al te vlug is geweest en of het niet juister zou zijn geweest de reeds begonnen proeven met een andere varieteit, n.l. de "Congo", langer voort te zetten. 
duur, schier onbetaalbaar. In Paramaribo bestaat het dekkleed van de straten uit schelpen, dat echter in den regentijd veel reparatie vereischt. Met dit alles blijft het wegenvraagstuk voor Suriname van urgent belang.

Ik weet, dat de door mij bezochte plantages, wel tot de beste en mooiste behooren. Allicht is dus mijn indruk te gunstig, ook aangaande de gebouwen. Maar hoe het ook zij, een feit is, dat bijv. de plantages Jagtlust, Peperpot en anderen gezien mogen worden en men het gevoel krijgt, dat er voor de arbeidersbevolking uitstekend wordt gezorgd. Wie zou op bedrijven van \pm 400 H.A. zulke hospitalen verwachten? Natuurlijk zijn er ook bedrijven waar het minder fraai is, doch over het algemeen wordt in Suriname, dank zij het Gouvernementstoezicht, goed voor den arbeider gezorgd. De Javaan, die uitkomt naar Suriname moet wel beseffen zeer door de Regeering beschermd te worden. Jammer, dat de planters zich tevreden moeten stellen met uitschot en ik kan mij best voorstellen hoe de planters met hand en tand vasthouden aan het beginsel "loon naar arbeid", en zich krachtig verzetten tegen het denkbeeld een minimum loon vast te stellen, onafhankelijk van de arbeidsprestatie, zooals dit mogelijk is in Oost-Indië, waar men een beter gehalte arbeiders heeft en een groote, vrije arbeidersbevolking op zijn plantage. Ook het streven naar afschaffing van de poenale sanctie, eveneens vallende in de lijn van de ethische richting, wordt door de planters als praematuur beschouwd. Wat toch mag men van een Javaan, die de prikkel mist om geld te maken boven de betaling van zijn levensbehoeften, verwachten, als hij niet door contractarbeid gebonden wordt, te meer, waar hij in het eerste jaar van zijn contract niet veel waard is, het tweede jaar bruikbaar wordt en eerst het derde jaar tot een volle arbeidskracht kan worden gerekend. Het schijnt dat voorlichters, die hun kennis en ervaring hebben opgedaan in onze Oost, zich van dat land moeilijk kunnen losmaken en voorstellen tot verbetering indienen, die misschien daar groote voordeelen kunnen hebben, maar voor Suriname niet passen en dientengevolge weerstand van de kant van de planters uitlokken. En deze weerstand geschiedt op goede basis, nu de plantersvereeniging onder leiding van haren voorzitter, den heer Mr. A. van Traa - een man hoog aangeschreven in de kolonie en wiens werkkring hem in nauwe aanraking brengt met de planterswereld - de vraagstukken, die van overheidswege worden voorgelegd, nauwkeurig bestudeert en haar oordeel behoorlijk motiveert. Als ik mij niet bedrieg, dan zit er leven in die planters-vereeniging en 
neemt de aaneensluiting der planters toe, naarmate de strijd in de bestaansvoorwaarden zwaarder wordt en spant men zich in om de middelen te vinden, die de cultuur zal vooruitbrengen. Er liggen tal van technische problemen in Suriname, niet het minst ten aanzien van afwatering, grondbewerking en verwerking van het produkt. Ze worden des te meer gevoeld naarmate de tijden moeilijker worden. Ik was getuige van een plantersdiscussie ten aanzien van een ziekte in de koffie (zeefvatenziekte), die wel is waar nog zeer is gelocaliseerd, maar ernstig kan worden, terwijl de oorzaak nog niet bekend is. Van deze discussie bewaar ik de herinnering, dat er onder de planters in Suriname flinke elementen zijn, die een vooruitstrevenden geest openbaren en volstrekt niet halsstarrig aan ingewortelde, oude denkbeelden vasthouden, maar wel degelijk gevoelen, dat men in de cultuur nog lang niet is waar men wezen moet. Het schijnt, dat planters uit OostIndië hunne collegas wel eens van conservatisme en achterlijkheid verdenken. Immers, de cultuur in onze Oost staat op zulk een veel hoogeren trap van ontwikkeling, maar - zij heeft ook een grooten voorsprong gehad door de veel gunstiger omstandigheden waaronder gewerkt werd, zelfs al is de bodem er veel duurder en lang niet zoo vruchtbaar als in Suriname. Misschien worden de prachtige resultaten van een aantal Indische ondernemingen ook wel te veel gegeneraliseerd en daardoor het povere resultaat bedekt van een aantal andere ondernemingen. In ieder geval stimuleerden de prachtige resultaten van verscheidene bedrijven de afvloeiing van kapitaal naar onze Oost en kon er veel geld worden besteed aan onderzoekingen en proefnemingen, hetgeen enorm tot verheffing van den landbouw in Indië heeft bijgedragen. Zit uit dien gezichtshoek Oost-Indië, Suriname uit een financieel oogpunt feitelijk in den weg, dan behoeft het niet zóó ver te gaan, dat vergelijkingen tusschen beide landen worden gemaakt, die onzuiver zijn. Dit was de ontvangen indruk, toen planters mij omtrent dit punt hunne meening gaven. Als demonstratie, dat de Oost-Indische planter niet te vlug moet zijn met zijn oordeel omtrent het beheer van een Surinaamsche plantage, diene het voorbeeld van eene onderneming waarop een gewezen administrateur uit Indië langzamerhand is teruggekomen van allerlei veranderingen naar Oost-Indisch plantagemodel ingevoerd. De practijk leerde hem, dat het werken op eene plantage in Indië en in Suriname twee zeer verschillende zaken zijn.

Wanneer ik in aanmerking neem al de tegenspoed bij de cultures in Suriname uit een zuiver technisch oogpunt ondervonden, 
dan bewonder ik de volharding en moed van de planters en is het mij een ergernis, dat deze specifieke eigenschappen van ons ras niet meer naar voren werden gebracht in de tallooze publicaties omtrent de kolonie. Liever wordt er gevit en gehakt op de Regeering. Aangenomen, dat daarvoor stof is, dan wil dit nog niet zeggen, dat de Regeering niet van goeden wil is. Ik kreeg volstrekt niet den indruk, dat er door onze Regeering zoo weinig gedaan wordt en nog minder, dat zij als het ware haar plicht tegenover de kolonie zou verzaken, zooals men uit sommige publicatiën zou moeten afleiden. Wel kan men verschillen van inzicht in de wijze waarop Nederland Suriname steunt. En ook begrijp ik hoe verderfelijk het is, dat telkens leidende ambtenaren worden vervangen door nieuwe, die zich wederom geheel in de toestanden moeten inwerken en verder, dat invloedrijke personen in ons land, die Suriname nooit gezien hebben, zich laten influenceeren door informaties uit niet altijd competente bronnen.

Wanneer men bedenkt, dat de welvaart van Suriname draait om het plantageleven, dan is zeker de tegenwoordige toestand niet rooskleurig. Maar deze schijnt hoopvoller te zijn geworden sedert eene lezing, die door den Heer S. H. Gongrijp in Nov. 1917 werd gehouden voor de plantersvereeniging. In die lezing deed men uitkomen, dat degenen, die in de laatste 35 jaren hun kapitaal in den Surinaamschen landbouw gestoken hebben weinig of geen rente van hun kapitaal gezien hebben. 48 ondernemingen, d.i. $60 \%$ van de bestaande plantages in de kolonie, zouden van eigenaars verwisseld en gekocht zijn voor nog geen $25 \%$ door elkander van de werkelijke waarde, terwijl onder de plantages, welke niet in andere handen overgingen er waren, die in geen 25 jaar een cent dividend aan hunne eigenaren konden uitkeeren. Er werd toen reeds op verlichting van de lasten bij de Regeering aangedrongen en dank zij de werkzaamheid van den lateren Gouverneur "Van Heemstra”, werd het aandeel in de transportkosten van de contractarbeiders weggenomen. Aangedrongen wordt nog steeds op den toevoer van meer arbeidskrachten, m.a.w. op immigratie op ruime schaal, want het zwakke punt van de kolonie is gelegen in een totaal onvoldoende bevolking. De toekomst van Suriname zou in de eerste plaats een bevolkingsvraagstuk zijn, te meer, daar de koffie meer arbeid eischt dan de cacaocultuur (o.a. door het oogsten het geheele jaar door, hetgeen dikwijls zeer storend inwerkt op ander werk, dat noodig gedaan moet worden).

Grond van uitstekende hoedanigheid is er echter ruimschoots in Suriname. Er kan dus op de meest gunstige voorwaarden grond 
in gebruik worden gegeven aan de kleine landbouwers. Deze kleine landbouwers zijn de arbeiders, die na hun contract op de plantage uitgediend te hebben, als vrije menschen in de kolonie blijven.

In de bevordering eener vestiging van kleine luyden op het platte land ziet men het voornaamste middel om de bevolking van de kolonie te vergrooten. Op de meest gemakkelijke voorwaarden kunnen de kolonisten grondperceelen in gebruik krijgen, zelfs zóó gemakkelijk, dat zij 6 jaren lang vrij zijn van eenige betaling voor huur, met het gevolg, dat zij gedurende die periode vaak roofbouw drijven, wetende daarna te kunnen overgaan op nieuwe perceelen op dezelfde voorwaarden. Dat er bij eene dergelijke opvatting van landbouw slordig en extensief wordt gewerkt is te begrijpen, maar toch zijn er Britsch-Indiërs, die goed geld in den kleinen landbouw hebben verdiend, al makt hun bedrijf op den Noordelijken cultuurman den indruk van een armoedig gescharrel. De geldzucht drijft hen tot hard werken en ongeloofelijk weinig uitgaven voor behuizing en levensonderhoud en het mag dan ook als een nadeel beschouwd worden, dat de emigratie uit Britsch-Indië niet meer wordt toegestaan. $\mathrm{Zij}$ heeft echter lang senreg sedduus am reeds in Suriname sene RritschIndische bevolking te doen ontstaan van \pm 25.000 zielen. Het is deze bevolking, die de ruggegraat is van den kleinen landbouw en de Regeering bevordert dan ook zooveel mogelijk de BritschIndiërs in den landbouw te houden, iets wat wordt tegengewerkt door het feit dat, zoodra zij meer ontwikkeling krijgen, tengevolge van het in de kolonie genoten onderwijs, zij neiging toonen in den handel te gaan, waarvoor zij veel aanleg hebben.

Naast de Britsch-Indische bevolking speelt de Javaansche bevolking een belangrijke rol in den kleinen landbouw. Deze bevolking is ook reeds \pm 25000 zielen en zal aangroeien nu de invoer van contractarbeiders uit onze Oost kan blijven voortgaan. Het maakt echter de ontwikkeling van den kleinen landbouw niet gemakkelijker, want de Javaan pakt niet aan, al moet men waardeeren dat hij netjes en zorgzuldig werkt en dientengevolge niet minder vatbaar zal zijn voor verbetering van zijn bedrijf als de Britsch-Indiër en - hij is rustig en eensgezind, waar de BritschIndiër woelig en lastig is. Echter, de Britsch-Indische bevolking vermeerdert zich sterker en is minder behept met ziekten dan de Javaansche, een verschil, dat speciaal voor Suriname van veel beteekenis is.

Toen de cacao nog een veilige cultuur was, had ook de kleine landbouwer daarvan inkomsten. Maar sedert deze cul- 
tuur zoo goed als geheel is verdwenen, is er in den kleinen landbouw overgebleven de teelt van gewassen, die weinig inbrengt. Veel groenten en vruchten worden er geteeld voor Paramaribo, maar de geldelijke opbrengst is dikwijls zeer miniem, daar de lokale markt spoedig overvoerd wordt en dientengevolge voor belachelijke prijzen moet worden verkocht. De export moet den kleinen landbouwer helpen en het is nu de vraag die gewassen te teelen, welke voor een loonenden export in aanmerking komen. Men heeft daartoe in de allereerste plaats het oog gericht op de rijstcultuur, die zoo belangrijk is opgekomen toen de kolonie gedurende den oorlog zich zelf van rijst moest voorzien. Groote terreinen (de lage, niet met bosch bezette vlakten) liggen er in Suriname, geschikt voor rijstcultuur en men heeft alle hoop daarop gevestigd te meer, omdat de Javaan van huis uit en uitstekend rijstbouwer is. Zuiverheid van soort en de voor Suriname meest geschikte varieteit, die zich tevens leent voor export, zullen door proefneming moeten worden verkregen, daarin gesteund door het proefstation onder leiding van den bekenden Prof. Stahel, die reeds jaren met vrucht in de kolonie als man van de wetenschap werkzaam is. Er schijnen nog meer producten te zijn, die nu ingevoerd worden, maar door den kleinen landbouw geleverd zouden kunnen worden en gedeeltelijk tot een exportartikel zouden kunnen worden opgewerkt, mits de beantwoording van de vraag in hoever daarbij geconcurreerd zal kunnen worden met andere landen, gunstig is. Ik hoorde o.a. noemen de teelt van sojaboonen, maar er valt met Mantsjoerije niet te concurreeren, zoodat men over dit product wel op ,home consumption" aangewezen zal zijn. Ook de sinaasappel mag de aandacht hebben, mits aanplant zoowel als uitvoer behoorlijk georganiseerd worden. Dan is mij opgevallen de achterlijkheid van de maiscultuur in verband met de resultaten, die in landen als bijv. Zuid-Afrika met veredeling zijn bereikt en waardoor de mais aldaar een belangrijk exportartikel is geworden.

Zeker is Suriname ten opzichte van het wereldverkeer niet gunstig gelegen en dit maakt het exportvraagstuk ten behoeve van den kleinen landbouw omvangrijk en ingewikkeld, maar onoplosbaar is het niet.

Meer dan ooit is het blijkbaar de Regeering ernst den kleinen landbouw in Suriname te ontwikkelen en daardoor de bevolking te vergrooten. Een landbouwconsulent uit onze Oost kwam tijddens mijn verblijf aan en ik meen, dat hem is opgedragen om te zien wat hij in de eerste plaats doen kan ter opheffing van den 
kleinen landbouw. Moge zijn werk meer effect hebben dan het eertijds ingevoerde landbouwonderwijs, dat op Nederl. grondslag wel is waar zeer degelijk was, maar waarvoor de Britsch-Indiër en Javaan nog niet rijp bleek te zijn.

Een opvallend verschijnsel is, dat sterk propaganda wordt gemakt voor de vestiging van Hollandsche boeren in Suriname. Van alle kanten is mij verzekerd geworden, dat een Noordelijke, ondanks zijn veel grootere spierkracht dan een Javaan of BritschIndiër, geen constitutie heeft, die hem het mogelijk maakt om veldwerk in een tropisch klimaat vol te houden, zooals dat op een klein bedrijf wordt vereischt. Hoogstens kan hij toezicht houden op het werk, maar voor die werkzaamheid is in het kleine bedrijf niet voldoende plaats.

Naar alles wat ik gezien en ondervonden heb van Holl. kolonisatie in andere landen valt het zeer te betwijfelen of onze boeren, verwend in het groote park "Nederland", zich in Suriname zullen thuis gevoelen, zelfs. wanneer zij ten opzichte van het landwerk in de meest gunstige conditie (bijv. op lichten grond) worden geplaatst. Wanneer men mocht verwijzen naar de Holl boeren, die bij Paramaribo wonen als de afstammelingen van de boeren, die eertijds in 1845 naar Suriname zijn geëmigreerd, dan zij medegedeeld, dat deze kolonie absuluut in verval verkeert. Wel is waar hebben deze Hollanders een periode van zekeren voorspoed gekend zoolang zij voor de levering van melk en groenten aan Paramaribo het monopolie hadden, maar dit hield op toen zij moesten concurreeren tegen de Britsch-Indiërs, zoodat nu hun bedrijf verloopt. Wij stappen hierbij nog over al de misère, die de oorspronkelijke Holl. kolonisten hebben doorgemaakt vóór zij zich konden vestigen nabij Paramaribo en vóór zij zich hadden aangepast in levenswijze, in taal en in wijze van werken. Ik meen, dat de Holl. Kolonie slechts mag genoemd worden als waarschuwing.

Een ander opmerkelijk verschijnsel is hoe van zekere zijde (de H.H. Dr. Th. Lens en J. A. Liems en consorten) een totale evolutie in den Surinaamschen landbouw wordt voorspeld, wanneer men maar zoo verstandig was mechanische grondbewerking in te voeren. Gewaagd wordt van moderne landbouwmachines met kabeltractie door Dyselmotoren op ponten gemonteerd in vereeniging met een nieuw systeem voor afwatering en inpoldering op een onontgonnen terrein (dus buiten het reeds in cultuur zijnde poldergebied), kortom een plan, dat voorzeker getuigt van grootschen opzet en veel durf, maar waar men in Suriname zeer scep- 
tisch tegenover staat, aangezien reeds genomen proeven met mechanische grondbewerking in Suriname geen gunstige resultaten hebben gegeven, in onze Oost de mechaniseering van het rijstbedrijf niet aan de verwachtingen heeft beantwoord en men zeer voorzichtig moet zijn met te verwijzen naar landen als N.-Amerika, waar de omstandigheden zoo geheel verschillen van die in Suriname. Blijkbaar is het niet de bedoeling met behulp van de reeds jaren lang in Suriname gevestigde Holl. kolonisten de levensvatbaarheid van het voorgestelde plan aan de practijk te toetsen - trouwens de eenige weg om vertrouwen te scheppen - ofschoon zij vrij wat beter bevoegd zijn de voorgespiegelde vooruitzichten te beoordeelen dan Holl. boeren, die de tropenwereld niet kennen. Voorts is het opvallend, dat men van eene propaganda voor het plan in Suriname zelf weinig of niets verneemt maar deze daarentegen sterk wordt doorgevoerd in ons land door middel van het maandblad "Nieuw Nederland" (Redactie Aagje Dekenstraat 16, Rotterdam), orgaan van het Nationaal Verbond tot Kolonisatiebevordering van Suriname en andere Nederlandsche gewesten. Zoolang er niet meer ervaring voorligt in de kolonie zelf, is het begrijpelijk dat men zeer gereserveerd is ten aanzien van de aangeprezen nieuwigheid, die het middel zou zijn om de kolonie er boven op te werken.

Ofschoon het tegen mijn gewoonte is over een land te schrijven, waar ik slechts korten tijd verbleef, meende ik deze keer in den vorm van losse indrukken eene uitzondering te moeten maken, ware het alleen om een ander geluid te doen hooren tegenover het vele pessimisme, dat men in publicaties van de laatste jaren maar al te dikwijls aantreft. Ik geloof dat men het vertrouwen in de toekomst van Suriname nog geenszins behoeft te verliezen.

Soorts-Hossegor.

Les Landes (Frankrijk).

\section{Noot van de redactie.}

Zie over den inmiddels door Prof. Stahel ontdekten verwekker van de zeefvatenziekte der koffie, de Indische Mercuur van 15 Oct. 1930. 
PRODUCTIE VAN SURINAME OVER TE LAATSTE ACHTTIEN JAREN

\begin{tabular}{|c|c|c|c|c|c|c|c|c|c|c|c|c|}
\hline Jaren & $\begin{array}{l}\text { Cacao } \\
\text { in balen } \\
\text { van } 100 \\
\text { Kilogr. }\end{array}$ & $\begin{array}{c}\text { Koffie } \\
\text { in ballen } \\
\text { van } 100 \\
\text { Kilogr. }\end{array}$ & $\begin{array}{l}\text { Suiker } \\
\text { in } \\
\text { tons }\end{array}$ & $\begin{array}{l}\text { Paddi } \\
\text { in } \\
\text { tons }\end{array}$ & $\begin{array}{l}\text { Mais } \\
\text { in } \\
\text { tons }\end{array}$ & $\begin{array}{l}\text { Cokos- } \\
\text { noten in } \\
\text { duizend } \\
\text { tallen }\end{array}$ & $\begin{array}{c}\text { Aard- } \\
\text { vruchten } \\
\text { in } \\
\text { duizend } \\
\text { tallen } \\
\text { kilogram }\end{array}$ & $\begin{array}{c}\text { Bananen } \\
\text { in } \\
\text { duizend } \\
\text { tallen } \\
\text { bossen }\end{array}$ & $\begin{array}{c}\text { Goud } \\
\text { in } \\
\text { K.G. }\end{array}$ & $\begin{array}{c}\text { Balata } \\
\text { in } \\
\text { tons }\end{array}$ & $\begin{array}{c}\text { Hout- } \\
\text { uitvoer- } \\
\text { waarde in } \\
\text { duizend } \\
\text { tallen } \\
\text { guldens }\end{array}$ & $\begin{array}{c}\text { Bauxiet } \\
\text { in } \\
\text { tons }\end{array}$ \\
\hline 1912 & 8640 & 1969 & 9634 & 2659 & 1291 & 968 & 1417 & 257 & 743 & 727 & 84 & - \\
\hline 1913 & 14782 & 3190 & 13244 & 2231 & 1076 & 822 & 1343 & 342 & 858 & 1186 & 128 & - \\
\hline 1914 & 14574 & $\cdot 4810$ & 15022 & 3136 & 878 & 876 & 1518 & 344 & 919 & 1019 & 60 & - \\
\hline 1915 & 14652 & 6097 & 14747 & 5280 & 1168 & 1015 & 2025 & 447 & 911 & 209 & 30 & - \\
\hline 1916 & 18709 & 7644 & 13032 & 7471 & 2254 & 1051 & 2307 & 520 & 798 & 769 & 31 & - \\
\hline 1917 & 19872 & 15460 & 14360 & 5338 & 1608 & 1449 & 4220 & 653 & 808 & 888 & 53 & - \\
\hline 1918 & 18877 & 18530 & 12086 & 8655 & 1874 & 2370 & 5571 & 734 & 586 & 681 & 31 & - \\
\hline 1919 & 13174 & 12824 & 7580 & 11388 & 1430 & 2468 & 4589 & 401 & 598 & 425 & 55 & - \\
\hline 1920 & 16023 & 17053 & 10077 & 9798 & 2078 & 2589 & 3991 & 385 & 470 & 444 & 244 & - \\
\hline 1921 & 15799 & 18124 & 11131 & 11797 & 1553 & 2216 & 3316 & 424 & 351 & 487 & 285 & - \\
\hline 1922 & 13606 & 25862 & 11906 & 12934 & 1713 & 2105 & 2085 & 484 & 374 & 546 & 142 & 13047 \\
\hline 1923 & 11606 & 28239 & 11785 & 10817 & 1538 & 2077 & 2160 & 489 & 396 & 629 & 146 & 12616 \\
\hline 1924 & 7951 & 16806 & 9068 & 16984 & 2206 & 2165 & 1885 & 480 & 323 & 555 & 80 & 60032 \\
\hline 1925 & 6956 & 25507 & 16612 & 13232 & 2582 & 2314 & 2031 & 520 & 309 & 735 & 130 & 86826 \\
\hline 1926 & 1402 & 17611 & 13965 & 16745 & 1718 & 1906 & 1855 & 378 & 259 & 563 & 232 & 46454 \\
\hline 1927 & 2107 & 30368 & 16736 & 14869 & 879 & 2233 & 1574 & 372 & 240 & 770 & 184 & 181584 \\
\hline 1928 & 2049 & 29238 & 18038 & 17476 & 916 & 2961 & 1658 & 348 & 171 & 511 & 318 & 213866 \\
\hline 1929 & 2790 & 28958 & 12763 & 23557 & 906 & 2850 & 2126 & 426 & 111 & 446 & 234 & 209998 \\
\hline
\end{tabular}

